\title{
Constructive realism: advantages of ontology and methodology
}

\author{
Andrey Tcytcarev ${ }^{1 *}$, Ruslan Bazhenov ${ }^{1}$, Elena Amineva ${ }^{2}$, and Aleksander Pronin ${ }^{2}$ \\ ${ }^{1}$ Sholom-Aleichem Priamursky State University, 679016, Birobidzhan, Russia \\ ${ }^{2}$ Ekaterinburg Academy of Contemporary Art, 620078, Ekaterinburg, Russia
}

\begin{abstract}
This article attempts to reveal and analyse the advantages of constructive realism as a methodological framework of contemporary science. Comparing realism and constructivism as two divergent positions in epistemology in their extreme forms, we mention their downsides. These are the epistemological component for extreme realism and the ontological component for radical constructivism. We indicate that the concept of our study is characterized with the best balance of ontology and gnoseology and it allows overcoming ontological and epistemological difficulties associated with constructivism and realism correspondingly. We conclude that constructive realism may facilitate the development of the scientific worldview pertinent to modern knowledge and ready to respond the inherent methodological challenges that science faces.
\end{abstract}

\section{Introduction}

Development of the gnoseo-ontological concepts complying with the state-of-the-art knowledge remains one of the key tasks of modern philosophy and scientific methodology. We suggest to direct attention to constructive realism. This concept receives different interpretations $[1,2,3]$, is further developed $[4,5,6,7]$ and is applied in empirical research. For example, it is used to study the peculiarities of religious culture [8] and psychology [9], specific issues of pedagogy $[10,11]$, problems of philosophy of history and culture [12] and sociology [13].

In this article, we endeavour to demonstrate the advantages of the concept and determine positive consequences of its application for contemporary science.

\section{Realism and Constructivism}

Gnoseological concepts in their most extreme interpretations exist in two divergent forms, namely realism and constructivism. The possibility for scientific cognition is based on the assumption that an objective reality exists and a human being as a cognizing subject essentially has access to it. Traditional epistemology suggested independence of the subject from the object and adopted realism as the main concept for the cognitive process

\footnotetext{
*Corresponding author: tcytcarev@yandex.ru
} 
description. Within the framework of this concept, a human being is believed to adequately reflect (describe and cognize) the perceived phenomena since he (his consciousness, mind) is not conditioned by anything and does not add anything on his own behalf. All cognition processes take place in a kind of space free from influence of the subject and his cognitive tools on the object of cognition. For a long time, the realistic cognitive attitude remained a key pillar of the scientific approach. Today, this approach has lost its dominating role in epistemology for a number of reasons.

For example, many scholars consider that the assumption that a person captures reality and reproduces it in concepts and categories with virtually no distortion "fails to adequately describe complex and multidimensional reality" [14]. First, due to its "dimensionality" human perception captures only a certain span of reality. Second, notions and categories used to theoretically define the empirical facts are the phenomena of consciousness rather than the objective reality. Some other opinions exist alongside with the preceding ones, such as that "representation is not only phenomenon in and of itself but a manifestation of the external world" [15]. However, we believe that these objections have ontological rather than epistemological nature.

Contemporary cognitive theory recognizes constructivism as a generally accepted, dominating concept. According to epistemological constructivism, cognition is a process of knowledge creation or construction. Radical constructivism denies that the cognizing subject is intrinsically related to reality itself. With reference to Kant's theory of the a priori forms of sense, cognitive capacity is essentially limited by the position of the subject. In a general sense, cognition is the process of establishing strong connections between objects in space and time. Since the only source of cognition is experience, cognition is solely possible through the senses. However, spatial and temporal forms of sensibility can be considered not only as a limitation of cognition, as it is assumed by constructivists, but also as its condition. Nevertheless, the adherents of this epistemological school greatly emphasize limitations of human cognitive abilities. The main thesis is the denial of cognition of reality as it is, independently from the cognizing subject (that is, then again, an ontological argument). Various authors develop this approach drawing on the findings in a number of disciplinary fields, such as genetic epistemology or developmental psychology [16], perceptual psychology [17], systems theory and cybernetics [18], anthropology [19], cognitive psychology [20], neurobiology [21] and psychotherapy [22]. Furthermore, it is assumed that the external world does exist, but we cannot perceive it as is in the process of cognition. In other words, the cognizing subject does not merely replicate the external world in his consciousness and in the results of cognition, but he actively participates in the process of knowledge construction.

Contemporary scientific knowledge suggests that a human being and a cognitive process may be examined more broadly. Human-world (subject-object) ontological relationship is a common notion of scientific methodology. Scientific findings are viewed from the perspective of an impact that fundamental characteristics of the human's place in the world have on them. These issues are thoroughly scrutinized by contemporary epistemology and philosophy of science within the framework of constructivism. Sociocultural factors affect inter alia the process of knowledge construction by a human being. Sociocultural reality of a human being determines a trajectory and sets out a direction for scientific and technological progress. As a part of culture, science is influenced from without. A type of scientific rationality that takes account of the influence that extra-scientific values have on the process of research and its findings is defined as post-non-classical [23]. The post-non-classical type of scientific rationality "takes into consideration not only the correlation of knowledge gained about the object with the peculiarities of the means and operations of activity but also with values and purposes of the subject [23, p. 327]. The form and quality of scientific facts, the content and types of 
scientific theories are dependent on the personal qualities and peculiarities of the subject and his worldviews that are further conditioned by cultural-historical, ethnical and other factors. Writing about "sociocultural dimensionality" of scientific foundations, V.S. Stepin notes that "... a type of scientific thought existing in the culture of a certain historic period is always co-related with the nature of communication and activity which people of this historic period are engaged in and is conditioned by its cultural context" [23, p.312]. This statement suggests that the concept of constructivism is universally recognized and, most likely, the most consistent at the present stage of development of science. However, so far as knowledge construction and its dependence on a variety of factors, both sociocultural and physical, biological, etc., is concerned, a clear tendency towards solipsism appears in the ontological part of the concept. Namely, we certainly cognize something, but do what we cognize and is there something at all. Philosophical foundations are an essential component of science that determine inter alia the ontology of mind (of the subject) and matter (of the object in the natural sciences). As a result of the dominance of constructive views in the modern theory of cognition, the question of the objectivity of cognition arose since radical forms of constructivism dispute interrelation of scientific cognition with the real world.

Hence, the problem of constructivism is in its ontology. Numerous researchers identify ontological issues in contemporary cognitive theory. For example, some assert that today "a critical need arises to build such theoretical models that would allow for ontological compatibility of the reality with a construct and would not rule out the possibility of existence for either of them" [24, p. 56]. In this case, the author does not deny the fact that "cognitive activity is intrinsically embedded in the sociocultural reality" and that "mental activity is essentially constructive" and features "the elements of sociality" but at the same time is not necessarily limited to the latter [24, p. 57].

If we attempt to combine constructivist and realist approaches, it could be noted that, on the one hand, the categories invented by a human being are always conditioned in one way or the other and their "cognitive potential" is determined by the peculiarities of the subject's cognitive tools but, on the other hand, it absolutely does not mean that we do not deal with the reality in this case. The epistemological designing is determined by interaction with the objects, the existence of which is available to us albeit through the lens of perception. Our knowledge about the object is just another way of its presentation to the cognizing subject.

\section{Constructive Realism}

In our view, constructive realism combines positive features of the two abovementioned approaches by making them less radical and smoothing over their contradictions. Austrian philosopher Fritz Wallner [25] is one of the founders of this concept. According to Wallner and his Viennese fellow scholars, constructive realism is a branch of philosophy that has been recently elaborated as an alternative to logical positivism that assumed any discourse on metaphysics devoid of meaning and avoided any speculations about reality. The present approach combines all principles of constructivism but does not exclude reference to reality along with that.

In the context of post-neoclassical scientific rationality, Aristotelian "embeddedness or disembeddedness of knowledge in the ontological context" [26, p. 18] becomes the criterion of truth. Embeddedness of knowledge in the ontological context implies, in some sense, a lack of "gap" or "distance" between the cognizing subject and the object of cognition. The object itself and knowledge about it (or the condition of the subject when he is able to perceive this knowledge) are ontologically described as existent and, in this sense, they appear to be the constituent parts the shared ontological "field". Such understanding of 
the subject and object of cognition falls within the framework of constructive realism. Subject and object in this case are constituent parts of a single reality. In regard to this concept, V.A. Lektorsky claims that "reality should be seen as multi-layered and multileveled" with "different levels existing separately from one another albeit interrelated inter se". Consequently, "we can say that "miscellaneous worlds" exist, each of which is real and connected to another ones" [27, p. 41].

In terms of ontology, constructive realism does not deny the existence of reality while, in terms of epistemology, this approach highlights the constructive character of cognition. Constructive realism distinguishes the notions of "actual reality" and "factual reality". The Austrian philosopher separates "the reality in the sense of the world without our cognitive process or the world we live in and the reality in the sense of the world being created solely in the course of cognition" [28, p. 20]. Actual reality (Wirklichkeit) is the reality itself, existing independently of the subject, while factual reality (Realität) is the reality constructed by a human being. This differentiation of notions refers to the Kantian concepts of "noumenon" and "phenomenon", but it does not follow the Kant's transcendental approach that suggests that the "thing-in-itself" corresponds with transcendental ego. However, within the framework of constructive realism, actual reality (Wirklichkeit) is as incognizable as the "thing-in-itself". Assuming that something is cognizable, this would be the "microworlds" constructed with our scientific and non-scientific experience and language. Although from the prospective of constructive realism, the incognizable reality is bound to exist as the surrounding medium we live and implement our scientific activities in, this medium is identified with the lifeworld and is not conceptually different from it.

On the other hand, factual reality (Realität) is seen as the sum total of "microworlds". The notion of "microworld" as one of the categories of constructive realism originated from Wittgenstein's argument that our ability to describe the reality is limited by our language use and each language-game is used to describe a specific lifeworld (form of the lifeworld). Hence, the term "microworld" was coined within the framework of constructive realism to define the reality constructed by various uses of language. However, constructive realism concurrently suggests that there is the sum total of all "microworlds" that may be defined as factual reality (Realität). This theory of two realities constitutes the ontology of constructive realism.

V.A. Lektorsky writes that a "human being does not exist without the world; he is a part of it and cannot ignore the complexity and, at times, unpredictability of the processes that he tries to interfere with. Thus, constructive realism is a contemporary philosophical attitude correspondent with the situation that has emerged as a result of development in science, technology and communicative social processes" [28, p. 39]. From our point of view, such ontology perfectly responds to the calls of the modern scientific methodology, the most important of which is justification of the objectivity of cognition. Premised on the existence of two types of reality, we should concurrently admit that the reality constructed in the process of scientific cognition is actual reality as well. Given all the assumptions and arguments of epistemological constructivism, ontology of constructive realism suggests that both the construct and the unknown and conceptually undifferentiated world are real.

In a similar vein, Stephen Hawking, prominent English theoretical physicist, considers that the process of cognition is always "theoretically loaded" and is based on the "specified" constructs that determine both the character of the cognizing subject's perception and the mode of problem setting. In this regard, Hawking's position who writes that "there is no picture- or theory-independent concept of reality" [29, p. 49] is especially illustrative. It is obviously a constructivist idea. For this reason, S. Hawking names a modern concept of reality in the natural sciences and in physics in particular the modeldependent realism. "The idea of model-dependent realism implies that any physical theory or world picture are represented by a model (normally, mathematical) and a set of rules that 
connect the model concepts to the observations". The position of classical realism was that reality existed "as-it-is-in-itself", independently of the observer. S. Hawking, however, claims that the findings of contemporary physics complicate substantiation of this position. Essentially, "model-dependent realism" suggests that any theoretical model should be accepted and used, whichever best complies with the requirement of observations and is less sophisticated than other models. According to S. Hawking, following this approach discrepancies between realism and constructivism may be eliminated [29].

We believe that the methodological approach defined as "model-dependent realism" does not diverge from the concepts of constructive realism and even corresponds with its concepts in many ways. What is most important is that this approach admits the constructive nature of scientific cognition while S. Hawking, as a true physicist, allows for the existence of the objective reality.

\section{Conclusion}

Based on the abovementioned, in our opinion, the use of the ontological and epistemological concept of constructive realism may result in positive changes for contemporary science.

First, the concept of two realities, namely as-it-is-in-itself and as-human-made, makes it possible to establish connections between natural and human sciences considering ontological unity of all phenomena (both natural and sociocultural). Such two-level ontology allows determining a new, wider knowledge scale. Practically, on the one hand, this approach allows orienting science beyond the achievement of the pragmatic results, on the other hand, it sets the benchmarks for the ideal dimensions of scientific development.

Second, provided that all phenomena of each "microworld" that is created within the framework of a particular scientific discipline comprise a shared ontological field of the single reality constructed by means of human cognitive tools, knowledge, in this case, may be transferred from one area of this ontological field into another, both for practical and cognitive purposes. Constructive realism may be used to create an epistemological strategy for the contemporary interdisciplinary research. Today, interdisciplinary research work becomes crucial for science due to social, as well as gnoseological reasons, however, epistemologically sound interdisciplinary research strategy is still missing. In these terms, constructive realism puts forward a strategy to use languages of one "microworld" in the other one. This refers to linguistic, as well as, to sociological and ontological conversions.

Third, the pragmatic view of science and its role in society takes on a new meaning. The notion of reality gets expanded and includes not only its cognizable and, to a certain extent, human-controlled area, but also its undifferentiated part. Consequently, it is critical for the modern scientific and technological activity to introduce ethical regulations. Following constructive realism, such regulations may be developed on the basis of the notion of reality that is not yet cognizable by a human being but that influences his existence and activity.

\section{References}

1. F. Wallner, Constructive realism. Aspects of a new epistemological movement (Braumüller, Vienna, 1994)

2. K. Bagheri Noaparast, Advances in Personal Construct Psychology, 3, 37 (1995)

3. B. Warren, Philosophical dimensions of personal construct psychology (Routledge, London, 1998) 
4. R. Madzia, Human Affairs, 23, 645 (2013)

5. V.A. Lektorsky, Revue philosophique de la france et de l etranger, 138, 171 (2013)

6. V.A. Lektorsky, Issues of philosophy, 5 (2017)

7. V. A. Lektorsky, Philosophy of Science and Technology, 23, 18 (2018)

8. F.G. Wallner, F. Lan, A. Schulz, Aspekte des Konstruktiven Realismus (Peter Lang $\mathrm{GmbH}$, Berlin, 2012)

9. F.G. Wallner, M.J. Jandl, Indigenous and Cultural Psychology (Springer, Boston, 2006)

10. K. Bagheri Noaparast, Journal of Curriculum Studies, 7, 81 (2013)

11. S. Zarghami-Hamrah, Aspects of Constructive Realism (Peter Lang, New York, 2012)

12. B. Pruzhinin, T. Schedrina, Epistemology and philosophy of science, 43, 27 (2015)

13. K. K. Hwang, Foundations of Chinese Psychology (Springer, New York, 2012).

14. N.N. Pluzhnikova, Vestnik NGU. Seriya: Filosofiya, 5, 19 (2007)

15. T. Rokmor, Epistemology and philosophy of science, 2, 35 (2005)

16. J. Piaget, Genetic Epistemology (Columbia University Press, New York, 1970)

17. U. Neisser, Cognition and reality: Principles and implications of cognitive psychology (Times Books, New York, 1976)

18. H. Foerster von, Cybernetics of cybernetics (Illinois, Urbana, 1974)

19. G. Bateson, Steps to an Ecology of Mind: Collected Essays in Anthropology, Psychiatry, Evolution, and Epistemology (Ballantine Book, New York, 1972)

20. E. Glasersfeld von, Radical Constructivism: A Way of Knowing and Learning (Falmer Press, Bristol, 1996)

21. H. Maturana, F. Varela, Autopoietic Systems: A Characterization of the Living Organization. Biological Computer Lab Report 9.4 (University of Illinois, Urbana, 1975)

22. P. Watzlawick, The language of change: Elements of therapeutic communication (Norton \& Co., New York, 1978)

23. V.S. Stepin, Philosophy of science. Points of concern (Gardariki, Moscow, 2006)

24. D.N. Bukin, Vestnik Tyumenskogo gosudarstvennogo universiteta, 50 (2012)

25. F. Wallner, Grenzziehungen zum Konstruktiven Realismus (WUV UP, Wien, 1993)

26. E.V. Bakeeva, Vestnik Vyatskogo gosudarstvennogo gumanitarnogo universiteta, 4, 11 (2012)

27. V.A. Lektorsky, Constructivism in the theory of cognition (IFRAN, Moscow, 2008)

28. V.A. Lektorsky, Constructivist approach in epistemology and human sciences (Kanon + , Moscow, 2009)

29. S. Hawking, L. Mlodinov, The highest design (Amforma, Sankt-Peterburg, 2012) 